\title{
PENERAPAN TEKTONIKA DAN BANGUNAN MODULAR DALAM PERANCANGAN PROYEK PENGAWASAN DAN REBOISASI HUTAN BEKAS TERBAKAR
}

\author{
Efraim Jusuf ${ }^{1)}$, Fermanto Lianto ${ }^{2)}$ \\ 1)Program Studi S1 Arsitektur, Fakultas Teknik, Universitas Tarumanagara, efraim9932@gmail.com \\ 2) Program Studi S1 Arsitektur, Fakultas Teknik, Universitas Tarumanagara, fermantol@ft.untar.ac.id
}

\begin{abstract}
Abstrak
Fenomena yang terjadi merupakan banyaknya deforestasi yang terjadi akibat kebakaran hutan saat musim kemarau yang membuat kawasan hutan menjadi kering. Hal ini membuat banyaknya lahan hutan yang bekas terbakar menjadi tandus tanpa dilakukannya reboisasi kembali. Sehingga hilangnya keanekaragaman hayati yang ada kawasan hutan itu dan merusak ekosistem yang ada. Diperlukannya suatu proyek untuk mereboisasi lahan hutan bekas terbakar untuk meminimalisir hilangnya keanekaragaman hayati dan bahkan mengembalikannya. Metode penelitian yang dilakukan difokuskan melalui literatur-literatur yang berhubungan dengan deforestasi. Metode desain yang diterapkan berdasarkan pada prinsip tektonik dan juga berfokus pada sistem bongkar pasang sehingga dapat memaksimalkan reboisasi pada lahan hutan tersebut. Selain itu menerapkan prinsip Kevin Lynch dalam konteks kota ke dalam hutan menjadi suatu pemikiran baru dalam merancang suatu proyek reboisasi di hutan. Hadirnya proyek reboisasi dan pengawasan hutan bekas terbakar ini diharapkan dapat menjadi salah satu contoh untuk meminimalisir hilangnya keanekaragaman hayati dan bahkan mengembalikannya sehingga ekosistem hutan yang menopang kehidupan manusia dapat bertahan dan tidak hilang.
\end{abstract}

Kata kunci: deforestasi; reboisasi; tektonik; bongkar pasang

\begin{abstract}
The phenomenon that occurs is the amount of deforestation that occurs due to forest fires during the dry season, making forest areas dry. That makes a lot of forest land that has been burned to be barren without reforestation. So that the loss of biodiversity in the forest area and damage the existing ecosystem. A project is needed to reforest burnt forest land to minimize biodiversity loss and even restore it. The research method focused on the literature related to deforestation. The design method applied is based on tectonic principles and focuses on the Knock-down system to maximize reforestation on the forest land. In addition, applying Kevin Lynch's principles in the context of the city into the forest becomes a new thought in designing a reforestation project. The presence of a reforestation project and monitoring of burned forests are expected to be an example to minimize the loss of biodiversity and even restore it so that the forest ecosystem that supports human life can survive and not be lost.
\end{abstract}

Keywords: deforestation; reforestation; tectonic; knock-down

\section{PENDAHULUAN}

Beyond Ecology menjadi suatu tema dan terdiri dari kata 'Ecology' yang diterjemahkan ekologi dalam Bahasa Indonesia memiliki makna berupa hubungan timbal balik antara makhluk hidup dan kondisi lingkungannya yang berupa alam sekitar (Kemendikbud, 2021), sedangkan 'Beyond' yang merupakan kata dalam Bahasa Inggris dan diterjemahkan sebagai 'melampaui'. Maka dari itu beyond ecology merupakan sesuatu yang lebih dari hubungan antara alam dengan makhluk hidup yang ada. 
Pada era modern ini percepatan dalam lingkup kehidupan manusia semakin tinggi. Lantas apakah beyond ecology ini dapat tercipta pada era modern ini? Dan bagaimanakah bentuk dari beyond ecology tersebut dalam kehidupan manusia?

Menurut David Attenborough dalam film documenter $A$ Life on Our Planet, manusia pada era modern ini manusia hidup di dunia yang terpisah dari alam liar yang ada dan hanya mengambil sumber daya yang diberikan alam tanpa memikirkan kondisi dari alam itu (Jonathan Hughes, 2020). Dengan terpisahnya manusia dengan alam itu dan percepatan dalam peradaban manusia ini menciptakan suatu 'kebutuhan' yang berlebih dari sumber daya alam itu tanpa memikirkan kapasistas yang dapat diberikan alam kepada kita.

Salah satu fenomena yang terjadi adalah deforestasi yang berlebihan dan dijadikan sebagai perkebunan tumbuhan monokultur, sehingga menyebabkan hilangnya keanekaragaman hayati yang ada dan merusak ekosistem di dalam hutan itu. Selain itu ditambah lagi dengan adanya deforestasi ilegal dan kebakaran hutan yang disengaja maupun tidak disengaja menyebabkan semakin menipisnya jumlah hutan yang berfungsi sebagai rumah bagi keanekaragaman hayati. Lantas hal ini menimbulkan masalah dimana lahan hutan yang bekas terbakar dibiarkan begitu saja. Selain itu kurangnya arsitektur yang mendukung dalam pengawasan juga memberi dampak sulitnya untuk melakukan pencegahan terhadap kebakaran hutan yang mungkin terjadi.

Untuk menanggapi hal ini maka dilakukannya proyek mereboisasi hutan yang bekas terbakar sehingga dapat kembalinya habitat bagi keanekaragaman hayati yang ada sebelumnya dan juga perlunya suatu arsitektur yang menjulang tinggi hingga dapat melihat ke sekeliling hutan sebagai pengawasan dan dapat lebih cepat mengidentifikasi masalah di hutan.

Dalam hal diperlukannya suatu ide dalam mengatasi kebakaran dan juga mereboisasi hutan yang ada. Dimana ide tersebut dapat meningkatkan kinerja para individu yang bertugas. Knock-down Architecture diusahakan dapat menjadi suatu jawaban untuk meningkatkan kinerja dari individu yang bertugas. Bangunan ini dapat dibongkar pasang sesuai dengan situasi dan kebutuhannya. Dimana tujuan proyek ini berupa mereboisasi lahan hutan yang bekas terbakar, meminimalisir dampak dari kebakaran hutan dan penebangan illegal dan mempertahankan atau bahkan meningkatkan kembali habitat bagi keanekaragaman hayati yang ada di kawasan hutan tersebut.

\section{KAJIAN LITERATUR}

\section{Ekologi}

Ilmu yang memperlajari hubungan antara organisme dan seluruh faktor biologi yang saling mempengaruhi dapat dikatakan sebagai ekologi (Pianka, 1988). Sven memperjelas dimana ekologi adalah bidang studi yang luas dan beragam. Salah satu perbedaan mendasar dalam ekologi adalah antara autecology (studi ekologi dari suatu organisme, atau terkadang spesies tertentu) dan sinecology (studi ekologi seluruh komunitas tumbuhan atau hewan), di mana yang pertama adalah dianggap sebagai ekologi organisme individu dan populasi, sebagian besar berkaitan dengan organisme biologis diri; dan yang terakhir, ekologi hubungan di antara organisme dan populasi, yang sebagian besar berkaitan dengan komunikasi material, energi, dan informasi dari seluruh system komponen (Jørgensen, 2009). Ekologi menitikberatkan pada suatu hubungan dan interaksi. Dimana interaksi terjalin antara biotik dan abiotik dalam segala faktor yang ada.

\section{Deep Ecology}

Ekosentrisme merupakan suatu teori etika lingkungan yang memusatkan etika pada seluruh komunitas ekologi, baik yang hidup maupun yang tidak hidup. Secara ekologis, makhluk hidup dan benda-benda abiotik lainnya saling terkait satu sama lain. Maka, kewajiban dan tanggung jawab moral tidak hanya berlaku pada makhluk hidup tetapi pada semua komponen ekologis yang ada (Hardjasoemantri, 2006). 
Deep ecology merupakan salah satu teori yang mengemukakan ekosentris, dimana deep ecology ini berpusat tidak hanya pada manusia melainkan pada seluruh makhluk hidup. Deep ecology ini mempersoalkan secara mendasar cara pandang dan pemahaman etika antroposentris dalam melihat hubungan manusia dengan alam (Keraf, 2006).

Fritjof Capra menyatakan bahwa cara pandang ekologi dangkal/shallow ecology yang bersifat antroposentris berbeda dengan ekologi dalam/deep ecology (Capra, 2013). Hal tersebut terlihat dari alam hanya sebagai suatu alat bagi manusia yang merupakan pusat dari semua nilai. Deep ecology tidak memisahkan segala hal dari alam yang ada. Deep ecology melihat dunia sebagai suatu ikatan fenomena yang saling bergantung dan terhubung, bukan hanya sebagai suatu kumpulan objek-objek tersendiri. Deep ecology memandang manusia hanya sebagai salah satu bagian khusus dalam jaringan kehidupan (the web of life) dan mengakui nilai-nilai instrinsik dari semua organisme yang ada. Pemikiran deep ecology ini menyiratkan suatu etika berorientasi pada ekologi yang baru, dimana kerangka etika yang terkait dengan pemikiran lama tidak sesuai dalam menghadapi masalah etika saat ini, yang menyebabkan ancaman terhadap organisme selain manusia (Capra, 1997).

Melalui pemikiran deep ecology, maka mendapatkan perlunya paradigma yang berpusat pada ekologi dan bukan hanya pada manusia. Kehidupan yang saling berinteraksi dan berdampingan antara alam dan manusia harus diusahakan, sehingga dapat mencapai suatu co-eksistensi antara manusia dengan alam yang ada.

\section{Architecture as Co-existence Between Human and Wildlife}

Banyaknya flora dan fauna yang terancam punah karena dampak dari manusia. Hal ini dikarenakan suatu keyakinan yang menyatakan bahwa manusia tidak dapat hidup berdampingan dengan alam liar. Keyakinan ini membuat segala program seperti konservasi dan lainnya yang berhubungan terletak di luar area alam liar dan timbulnya segregasi antara manusia dengan alam liar itu. Hal ini menyebabkan sulitnya suatu co-eksistensi antara manusia dan alam liar. Dengan berkembangnya jumlah manusia yang pesat akan memunculkan suatu urgensi untuk hidup yang saling berdampingan antara manusia dan alam liar tersebut (Carter, Shrestha, Karki, Pradhan, \& Liu, 2012).

Diagram skematis ini merupakan contoh pertimbangan kehidupan yang berdampingan antara manusia dengan satwa liar (Carter, Shrestha, Karki, Pradhan, \& Liu, 2012).

1) Co-eskistensi satwa liar dan manusia dalam skala regional.

Dengan adanya pemisahan zona spasial yang berbeda, hal ini merupakan fenomena yang sedang terjadi sampai sekarang.

2) Co-eksistensi satwa liar dan manusia dalam skala menengah yang relatif lebih kecil.

Area yang dikelola masyarakat, di mana orang dapat mengekstraksi sumber daya alam secara terbatas, seperti peternakan dan komunitas yang pro-satwa liar hutan, mendorong koeksistensi pada skala menengah yang relatif lebih kecil.

3) Co-eksistensi satwa liar dan manusia dalam skala yang lebih baik.

Adanya keberadaan manusia yang berada di tengah alam liar itu, sebagai penghubung dan juga sebagai pengawas untuk menciptakan suatu keharmonisan antara manusia dan satwa liar yang ada. Tetapi hal ini juga harus didukung dengan penggunaan sumber daya yang tidak berlebihan dan dibatasi dengan baik (lihat gambar 1). 

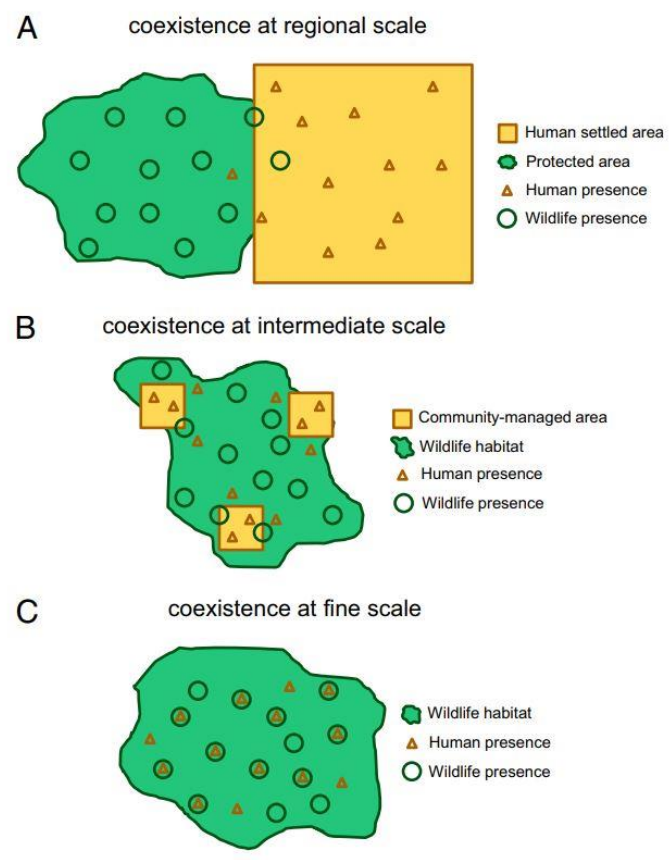

Gambar 1. Diagram Skematis Co-eksistensi antara manusia dan satwa liar.

Sumber: Coexistence between wildlife and humans at fine spatial scales (Carter, Shrestha, Karki, Pradhan, \& Liu, 2012)

Melalui diagram yang ada (lihat gambar 1), dapat disimpulkan bahwa untuk menuju suatu co-eksistensi antara manusia dan alam liar tetap diperlukannya co-eksistensi dalam skala regional dan menegah. Untuk subjek yang langsung ber co-eksistensi langsung dengan alam liar yang ada lebih terfokus pada individu ataupun organisasi yang berhubungan dengan keberlangsungan alam liar itu. Sehingga merekalah yang menjadi jembatan kehidupan co-eksistensi antara manusia dan alam liar.

\section{Fire Lookout/Observation as Bridge to Co-existence}

Menara pengawas api yang hanya merupakan bangunan arsitektur yang simple tetapi memiliki dampak yang besar bagi Hutan yang ada. Dimana sebagai garis terdepan dalam memerangi kebakaran hutan yang sering terjadi. Sebagai sumber pemberi informasi pertama mengenai kebakaran hutan maupun penebangan hutan illegal, namun tidak dapat langsung tanggap menghadapi kebakaran maupun penebangan liar yang ada.

Selain itu dengan kehadiran manusia secara 24 jam mungkin juga dapat membantu pengawasan ini agar dapat lebih maksimal. Dengan adanya pemukiman manusia yang masih memprioritaskan ekosistem dalam hutan tersebut diharapkan dapat menjadi pengawas dan penanggung jawab dalam menjaga kelestarian keanekaragaman hayati yang ada. Khususnya bagi para petugas-petugas yang mereboisasi hutan dan juga polisi hutan yang membantu mengawasi hutan sekitarnya.

\section{The Image of the City}

Penggunaan prinsip-prinsip Kevin Lynch dalam bukunya The Image of the City dan diterapkan di hutan. Dimana teori tersebut berupa (Lynch, 1960):

1) Path merupakan jalan yang dapat dilalui oleh manusia. Path merupakan sirkulasi yang digunakan sebagai tempat untuk bergerak dari titik satu ke titik yang lain dan tercipta melalui adanya batasan imajiner.

2) Edges ini tidak digunakan sebagai sirkulasi bagi manusia dan merupakan elemen yang bersifat linear. Elemen ini berfungsi sebagai batasan yang membatasi suatu kawasan sehingga terciptanya suatu privasi dan wajah dari kawasan tersebut. 
3) District berupa suatu kawasan yang bersifat dua dimensi yang memiliki skala menengah hingga luas, dimana manusia dapat keluar dan masuk ke kawasan tersebut. Setiap kawasan ini memiliki ciri-ciri yang bersifat homogen.

4) Nodes merupakan titik atau spot dimana manusia dapat masuk dan berkumpul di dalamnya, dan merupakan titik pusat dari dan kemana manusia ini bergerak. Nodes ini dapat berupa tempat berhenti sejenak, persimpangan jalan, pertemuan atau persilangan jalan, atau bahkan ruang terbuka.

5) Landmark merupakan titik seperti nodes, hanya saja manusia lebih fokus untuk melihat dibanding masuk ke dalamnya. Landmark itu sendiri merupakan suatu elemen yang lebih fokus pada bentuk visual yang mencolok.

Penggunaan teori Kevin Lynch ini didasarkan pada pengertiannya dan dimasukkan ke dalam sektor hutan, sepertinya perlunya landmark dalam hutan sebagai titik penanda agar setiap manusia yang ada di dalam hutan itu tidak mudah tersesat. Selain itu, komponen-komponen hutan lainnya dapat diandaikan menurut teori Kevin Lynch lainnya.

\section{METODE}

Dalam merancang sebuah arsitektur, ada banyak sekali pendekatan-pendekatan yang dapat dilakukan. Pendekatan ini merupakan suatu metode dalam merancang dan menganalisis objek rancangan sehingga dapat berjalan dengan efektif. Hal ini dapat digunakan untuk mengatur system konstruksi, program ruang, visualisasi ruang dan tatanan ruang yang ada. Pendekatan ini dapat dipilih oleh perancang sesuai dengan metode dan objek yang akan dirancang sehingga dapat membantu dalam proses merancangnya (lihar gambar 2).

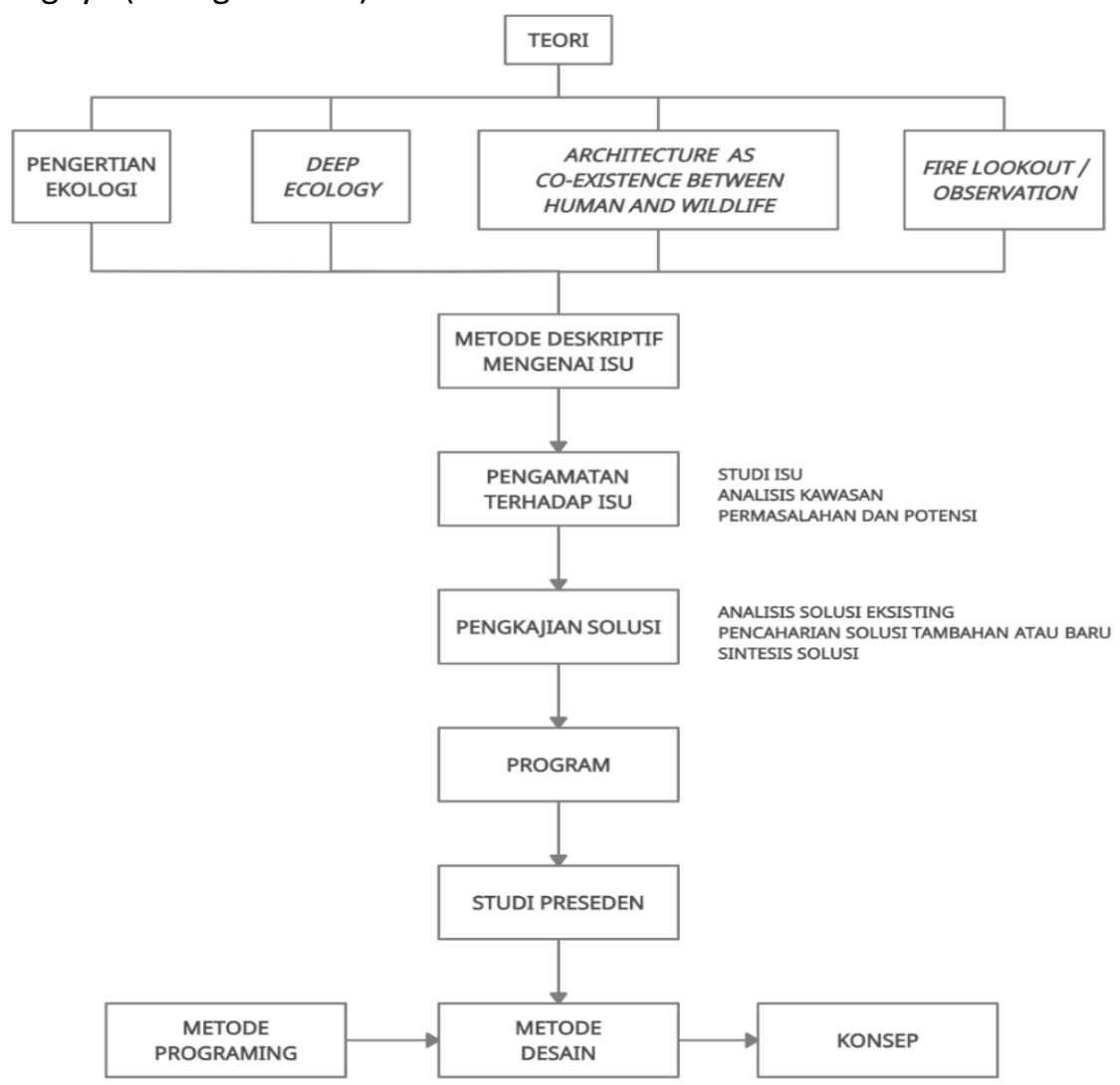

Gambar 2. Diagram Metode Penelitian

Sumber: Penulis, 2021 
Salah satu pendekatan yang dapat dilakukan berupa pendekatan tektonik. Dimana pada pendekatan ini, tektonika suatu bangunan dapat ditonjolkan menjadi suatu keindahan bagi arsitektural tersebut. Dimana konstruksi dan struktur dari arsitektur tersebut menjadi esensi bagi bentuk arsitektur itu sendiri (Frampton, 2004).

Metode tektonik merupakan sebuah metode desain yang bergerak dalam kemampuannya membangun keindahan melalui material dan hubungan konstruksi (lihat gambar 3). Dimana arsitek harus dapat jeli dalam bereksplorasi terhadap keindahan konstruksi serta melihat berbagai macam hubungannya dalam referensi budaya, menjadi sebuah cara untuk menghasilkan kekuatan dari tektonik itu sendiri (Sutanto, 2020).

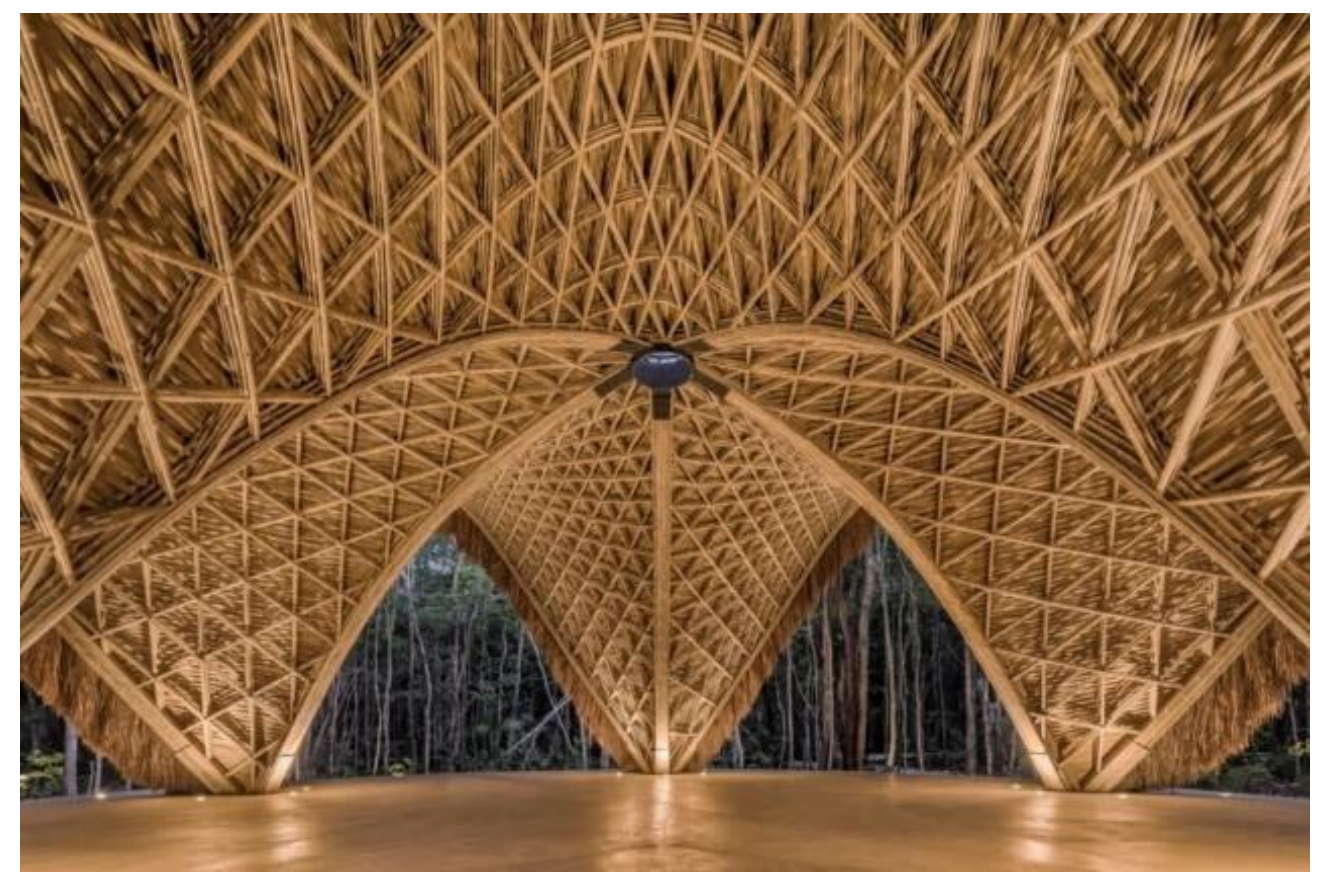

Gambar 3. Bamboo Luum Temple

Sumber: (https://inhabitat.com/bamboo-luum-temple-preaches-sustainable-development-intulum/luum-temple-by-co-lab-design-office-10/) Diakses 1 Mei 2021

Dalam perancangannya akan diterapkan suatu arsitektur yang bersifat modular dan knock-down untuk mempermudah pembangunan di tapak yang ada. Selain itu dengan system modular ini juga memungkinkannya untuk dibangun di area lain yang mengalami isu yang sama. Selain itu menerapkan prinsip-prinsip Kevin Lynch dalam bukunya 'The Image of the City' ke dalam proyek dalam hutan. Penerapan ini mengimplementasikan komponen-komponen yang ada dalam hutan itu menjadi objek dalam prinsip Kevin Lynch.

\section{DATA KAWASAN}

Indonesia telah mengalami penurunan deforestasi dalam beberapa tahun terakhir. Dimana terlihat pada tahun 2018 deforestasi yang mencapai 440.000 hektar, menurun sedikit dari deforestasi yang terjadi pada tahun 2017 yang mencapai 480.000 hektar.

Meskipun terjadi penurunan pada skala nasional, angka deforestasi ini masih meningkat di beberapa provinsi yang mayoritasnya hutan primer dan lahan gambut (lihat gambar 4). Pada tahun 2018 peningkatan deforestasi ini terjadi disbanding tahun sebelumnya. Khususnya di Provinsi Kalimantan Timur 43 persen, Maluku 40 persen, dan Papua Barat 36 persen (Arief Wijaya, 2019). 


\section{Kehilangan Hutan Primer di Indonesia}

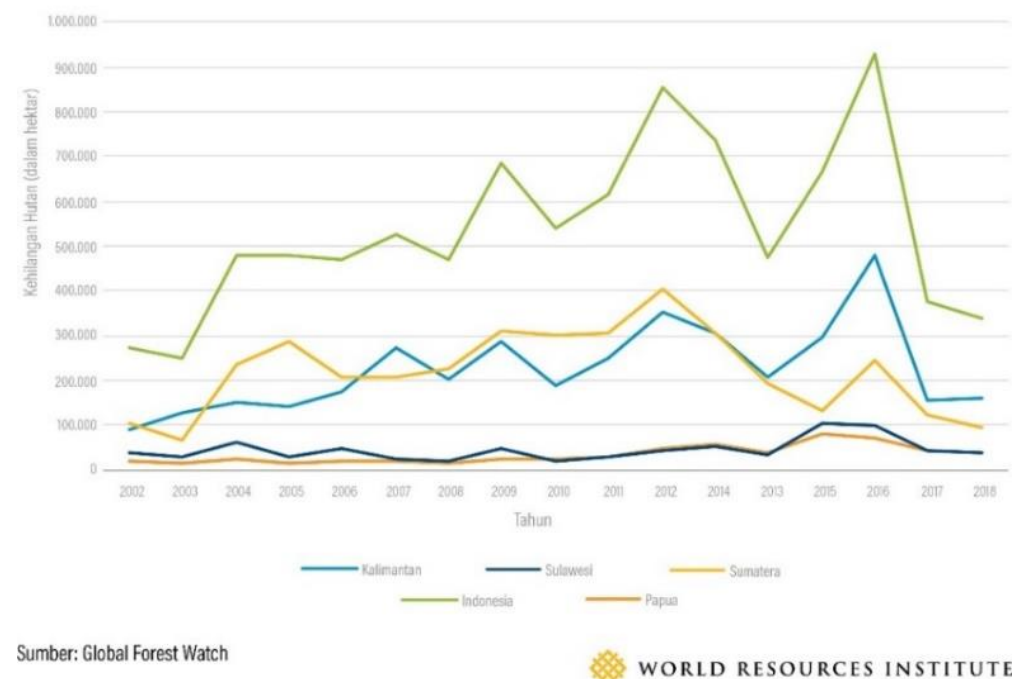

Gambar 4. Grafik kehilangan hutan primer di Indonesia

Sumber: (https://wri-indonesia.org/id/blog/indonesia-telah-mengurangi-penggundulan-hutan-tetapimasalah-masih-ada) Diakses 1 Juli 2021

Dari tabel terlihat bahwa Pulau Kalimantan memiliki luasan lahan dan hutan yang paling besar dalam hal kebakaran hutan (lihat Tabel 1). Khususnya Provinsi Kalimantan Tengah yang memiliki total luas area yang terbakar hampir satu juta hektar.

Tabel 1. Tabel Luas Hutan yang Terbakar

Rekapitulasi Luas Kebakaran Hutan dan Lahan (Ha) Per Provinsi Di Indonesia Tahun 2015-2020

\begin{tabular}{|c|c|c|c|c|c|c|c|}
\hline \# & PROVINSI & 2015 & 2016 & 2017 & 2018 & 2019 & 2020 \\
\hline 1 & Aceh & 913,27 & $9.158,45$ & $3.865,16$ & $1.284,70$ & 730,00 & $1.078,00$ \\
\hline 2 & Bali & 373,46 & - & 370,80 & $1.013,76$ & 373,00 & 29,00 \\
\hline 3 & Bangka Belitung & $19.770,81$ & - & - & $2.055,67$ & $4.778,00$ & 576,00 \\
\hline 4 & Banten & 250,02 & - & - & - & 9,00 & 2,00 \\
\hline 5 & Bengkulu & 931,76 & $1.000,39$ & 131,04 & 8,82 & 11,00 & 221,00 \\
\hline 6 & DKI Jakarta & - & - & - & - & - & - \\
\hline 7 & Gorontalo & $5.225,89$ & 737,91 & - & 158,65 & $1.909,00$ & 80,00 \\
\hline 8 & Jambi & $115.634,34$ & $8.281,25$ & 109,17 & $1.577,75$ & $56.593,00$ & $1.002,00$ \\
\hline 9 & Jawa Barat & $2.886,03$ & - & 648,11 & $4.104,51$ & $9.552,00$ & $2.344,00$ \\
\hline 10 & Jawa Tengah & $2.471,70$ & - & $6.028,48$ & 331,67 & $4.782,00$ & $7.516,00$ \\
\hline 11 & Jawa Timur & $7.966,79$ & - & $5.116,43$ & $8.886,39$ & $23.655,00$ & $19.148,00$ \\
\hline 12 & $\begin{array}{l}\text { Kalimantan } \\
\text { Barat }\end{array}$ & $93.515,80$ & $9.174,19$ & $7.467,33$ & $68.422,03$ & $151.919,00$ & $7.646,00$ \\
\hline 13 & $\begin{array}{l}\text { Kalimantan } \\
\text { Selatan }\end{array}$ & $196.516,77$ & $2.331,96$ & $8.290,34$ & $98.637,99$ & $137.848,00$ & $4.017,00$ \\
\hline 14 & $\begin{array}{l}\text { Kalimantan } \\
\text { Tengah }\end{array}$ & $583.833,44$ & $6.148,42$ & $1.743,82$ & $47.432,57$ & $317.749,00$ & $7.681,00$ \\
\hline 15 & $\begin{array}{l}\text { Kalimantan } \\
\text { Timur }\end{array}$ & $69.352,96$ & $43.136,78$ & 676,38 & $27.893,20$ & $68.524,00$ & $5.221,00$ \\
\hline 16 & $\begin{array}{l}\text { Kalimantan } \\
\text { Utara }\end{array}$ & $14.506,20$ & $2.107,21$ & 82,22 & 627,71 & $8.559,00$ & $1.721,00$ \\
\hline 17 & Kepulauan Riau & - & 67,36 & 19,61 & 320,96 & $6.134,00$ & $8.805,00$ \\
\hline 18 & Lampung & $71.326,49$ & $3.201,24$ & $6.177,79$ & $15.156,22$ & $35.546,00$ & $1.358,00$ \\
\hline 19 & Maluku & $43.281,45$ & $7.834,54$ & $3.918,12$ & $14.906,44$ & $27.211,00$ & $20.270,00$ \\
\hline 20 & Maluku Utara & $13.261,10$ & 103,11 & 31,10 & 69,54 & $2.781,00$ & 59,00 \\
\hline
\end{tabular}

Sumber: (http://sipongi.menlhk.go.id/hotspot/luas_kebakaran) Diakses 1 Juli 2021 
Pada tabel titik panas di bawah menunjukan Provinsi Kalimantan Barat yang memiliki titik panas yang cukup banyak (lihat tabel 2). Tetapi ketika berjalan memasuki musim hujan titik panas itu mulai menurun dengan drastis dan menghilang. Sedangkan di Provinsi Kalimantan Tengah titik api tidak berjumlah banyak tetapi tetap berada di angka yang konsisten.

Tabel 2. Tabel Jumlah Persebaran Titik Panas

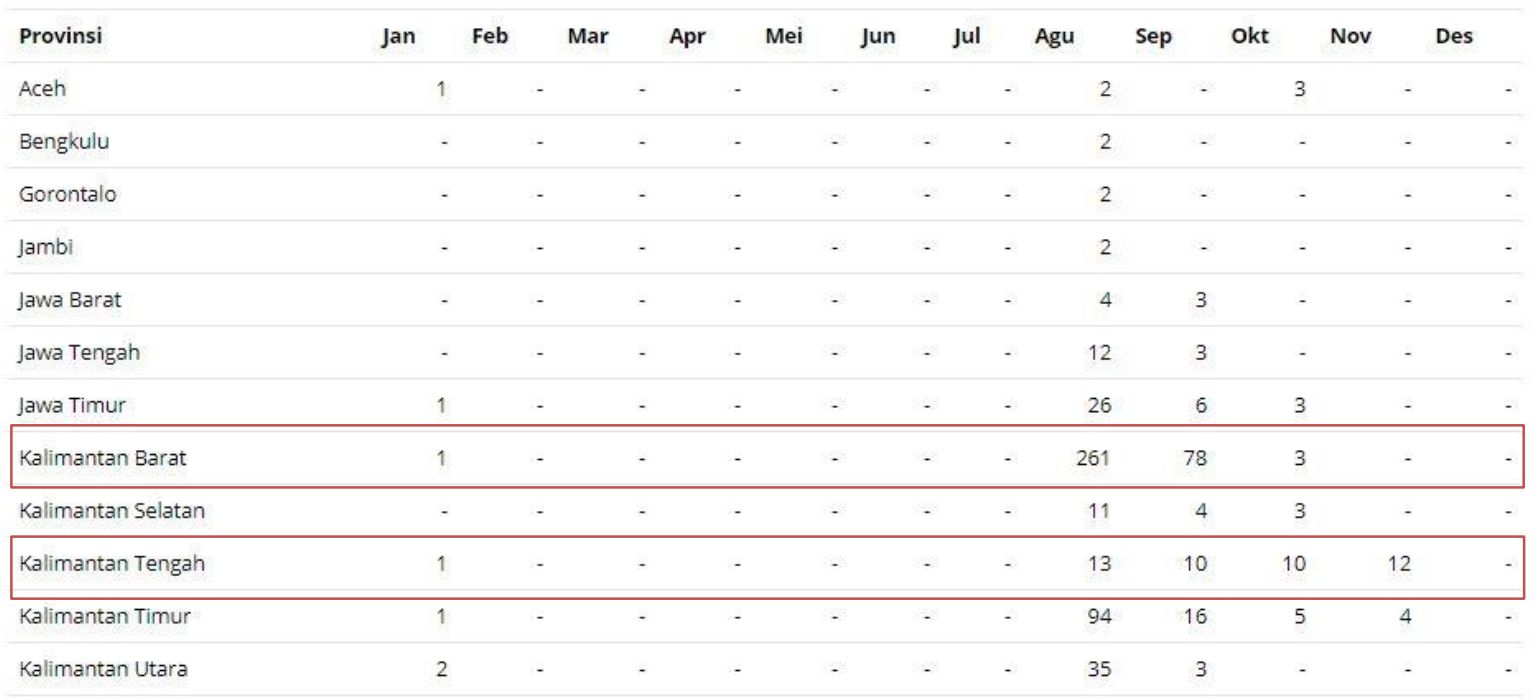

Sumber: (http://sipongi.menlhk.go.id/hotspot/matrik_tahunan?satelit=LPN-NPP\&thn=2020) Diakses 1 Juli 2021

Kalimantan Tengah merupakan kawasan dengan kondisi rawan api tertinggi. Ada dua kabupaten atau kota yang sangat rawan api yaitu Pulang Pisau dan Palangka Raya. Sepanjang Bulan Januari sampai 15 Agustus 2019, hotspot tertinggi berada di Palangkarayadengan jumlah 902, dari total 3.380 hotspoty yang ada. Dalam periode Januari-15 Agustus 2019, terdapat 494 dari 910 kejadian. Dari aspek luasan yang terbakar, Palangka Raya memiliki luasan tertinggi dengan 1.222,68 hektar selama periode Januari - 15 Agustus (Baskoro, 2019).

Letak kebakaran hutan yang terjadi berada tidak jauh dari kota Palangka Raya (Lihat gambar 5). Jaraknya berkisar 10-15 kilometer dari kota Palangka Raya. Titik kebakaran yang terjadi dekat Kota Palangkaraya ini akan digunakan sebagai tapak untuk membangun arsitektur yang akan menjawab isu ini, sehingga dapat mengembalikan hutan yang ada pada awalnya.
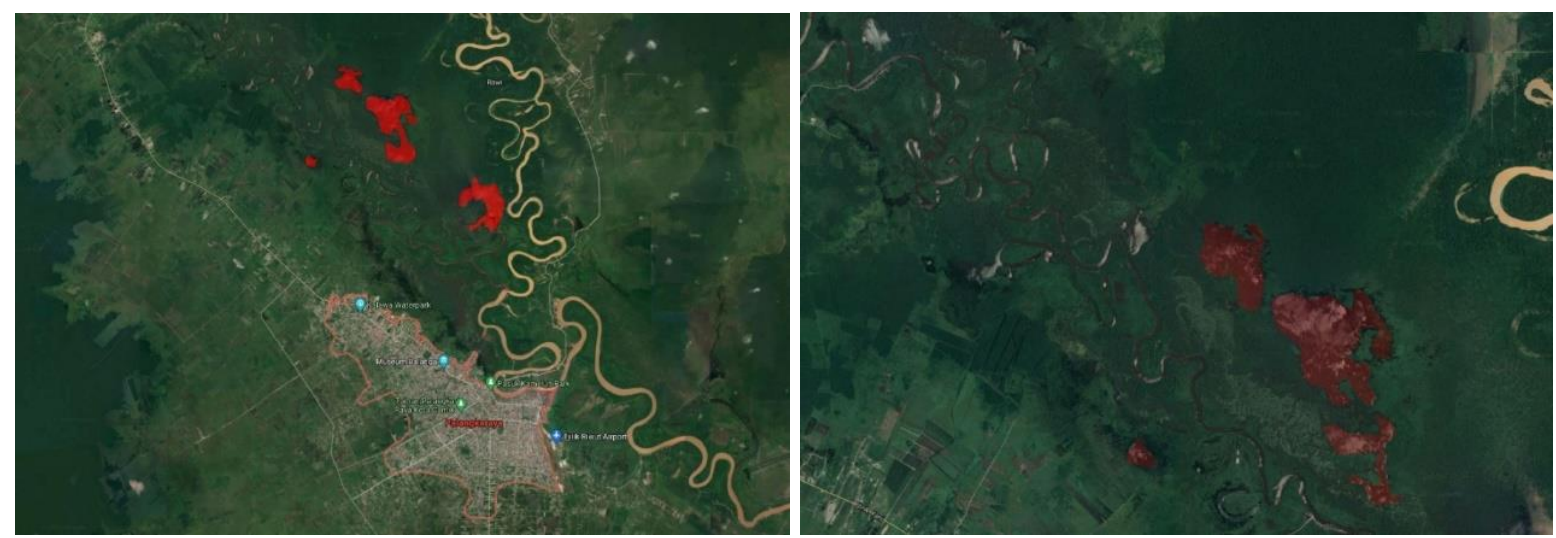

Gambar 5. Kota Palangka Raya dan Titik Kebakaran Hutan.

Sumber: (https://www.google.com/maps/place/Palangkaraya) Diakses 1 Juli 2021 


\section{DISKUSI DAN HASIL}

Melalui data kawasan yang didapat, menetapkan lahan hutan bekas terbakar yang dekat dengan Palangka Raya menjadi fokus dalam melakukan reboisasi. Secara eksisiting sudah terbentuk beberapa komponen dari prinsip Kevin Lynch (lihat gambar 6). Melalui ini akan dikembangkan lagi proses desain melalui prinsip ini. Mulai dari penambahan cluster-cluster yang ada, letak-letak massa yang akan tercipta dan juga situasi ketika proses reboisasi dan selesainya reboisasi.

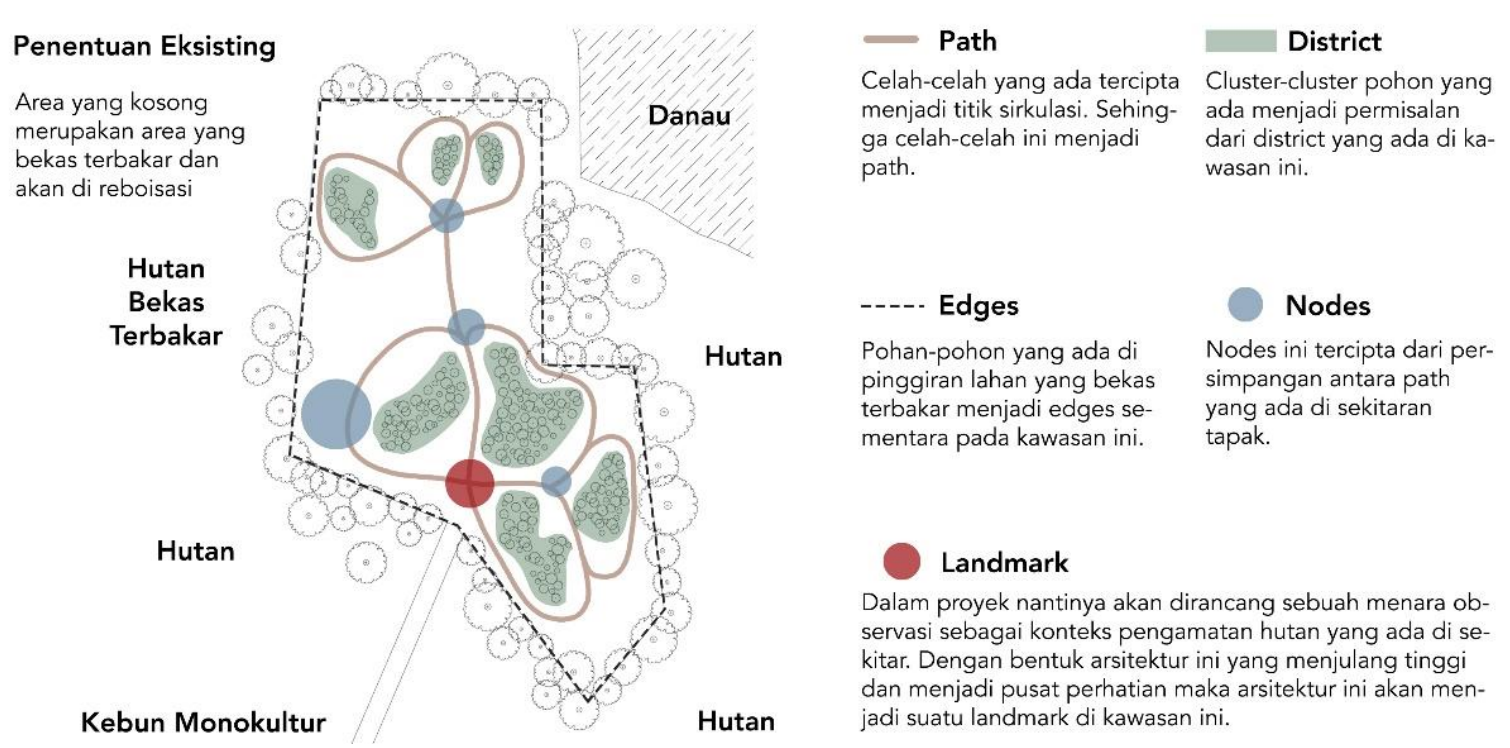

Gambar 6. Penentuan prinsip Kevin Lynch secara eksisting. Sumber: Penulis, 2021

Dari path yang ada dibuat sirkulasi utama dalam area reboisasi yang dijadikan perkerasan untuk mempermudah akses kendaraan yang akan membawa modul bangunan dan kebutuhan untuk reboisasi. Sirkulasi yang dijadikan perkerasan ini terhubung dengan akses masuk area reboisasi ini.

Sedangkan path-path lainnya yang ada di dalam area reboisasi akan berupa jalan tapak yang sengaja tidak akan ditumbuhi tanaman untuk mempermudah pengontrolan tanaman-tanaman yang baru di reboisasi (lihat gambar 7). Dan setelah selesai tahapan reboisasi yang ada maka akan dibiarkan tanah itu ditumbuhi secara alami.

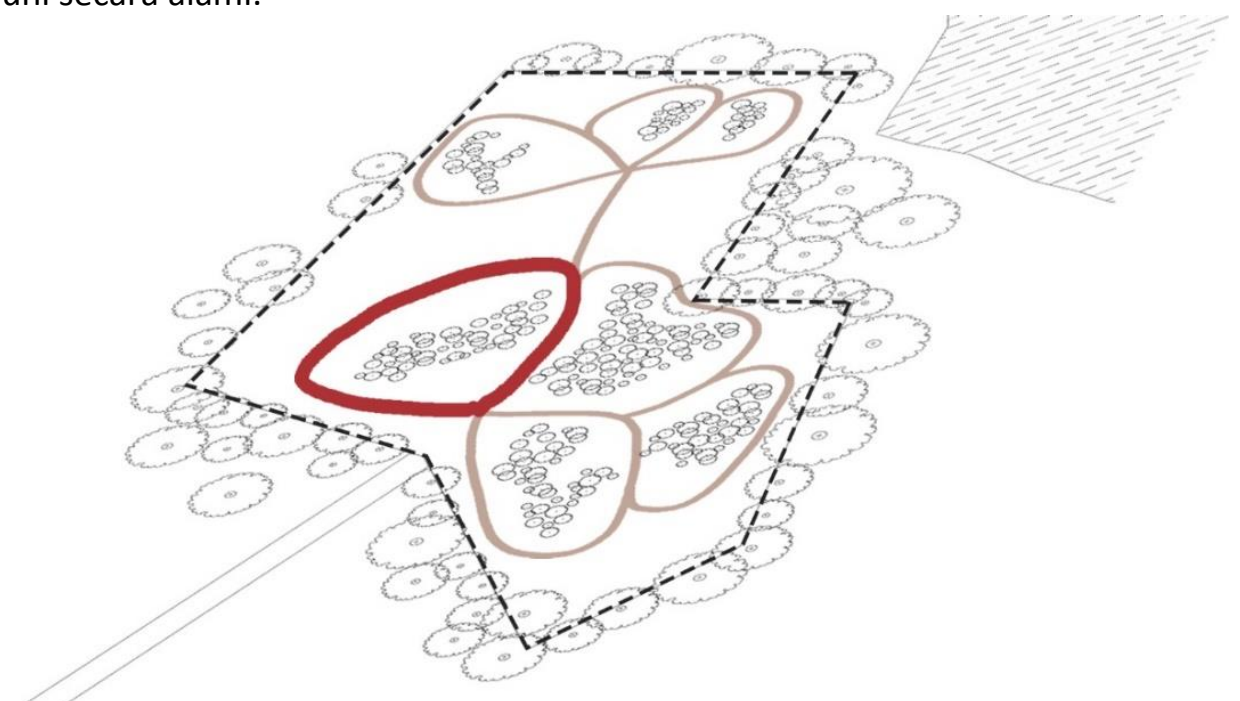

Gambar 7. Penentuan path utama.

Sumber: Penulis, 2021 
Area-area yang membatasi path akan dibuat menjadi cluster-cluster dalam mereboisasi untuk memaksimalkan area yang ada. Jenis tanaman percluster akan beragam sesuai dengan keanekaragaman hayati yang telah diteliliti di area hutan yang bekas terbakar tersebut.

Dengan pembagian cluster terciptanya jarak imajiner ini untuk menciptakan jalur angin (lihat gambar 8). Sehingga ketika musim kemarau angin yang bertiup akan membawa uap air yang berasal dari danah yang ada sehingga memberi kelembaban udara.

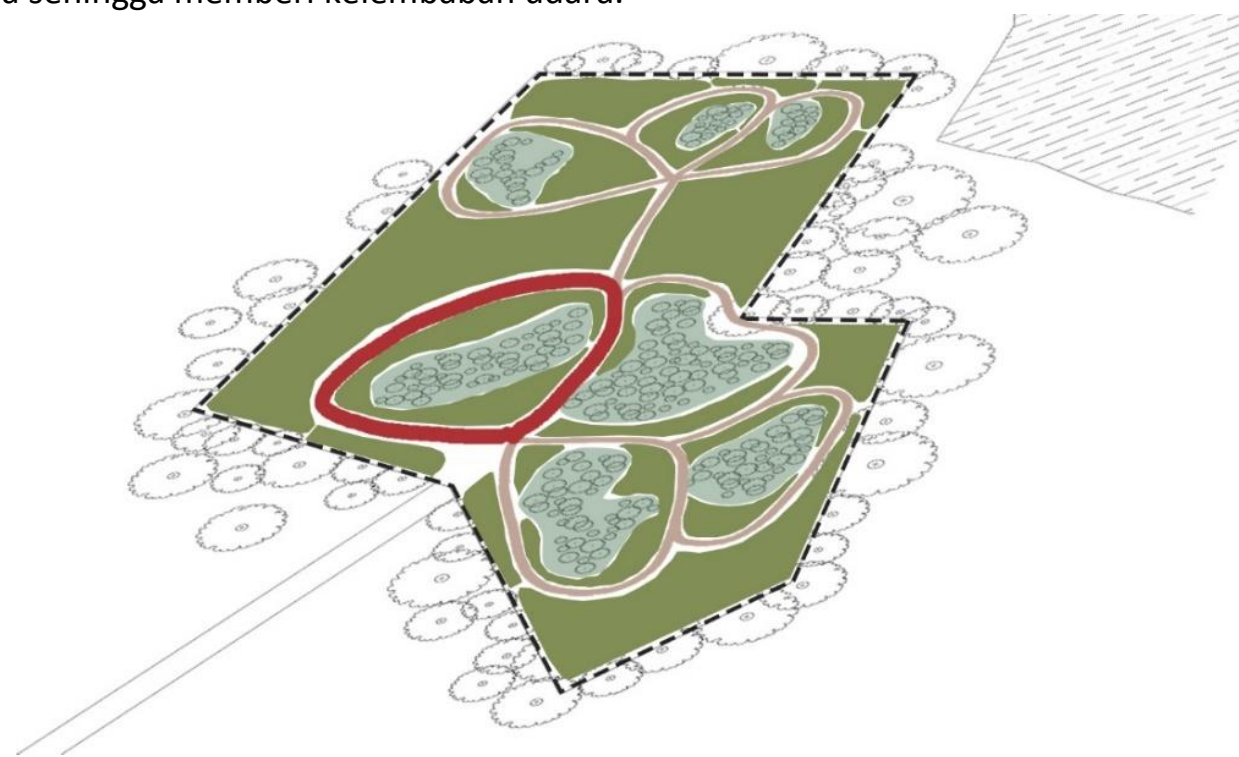

Gambar 8. Penentuan cluster-cluster reboisasi.

Sumber: Penulis, 2021

Massa-massa dalam proses reboisasi akan difokuskan diletakkan di titik-titik nodes yang ada (lihat gambar 9). Hal ini dilakukan juga untuk mempermudah akses ke area-area yang akan di reboisasi. Orientasi modul massa mess dan tempat pembibitan akan menghadap ke orientasi sesuai dengan musim yang ada. Peletakan orientasi yang berbeda guna agar dapat melakukan pembibitan yang berkelanjutan. Untuk menara observasi ditetapkan sebagai sebuah landmark dan diletakkan sebagai titik pusat dari sirkulasi yang ada dan juga dapat langsung dilihat dari jalan.

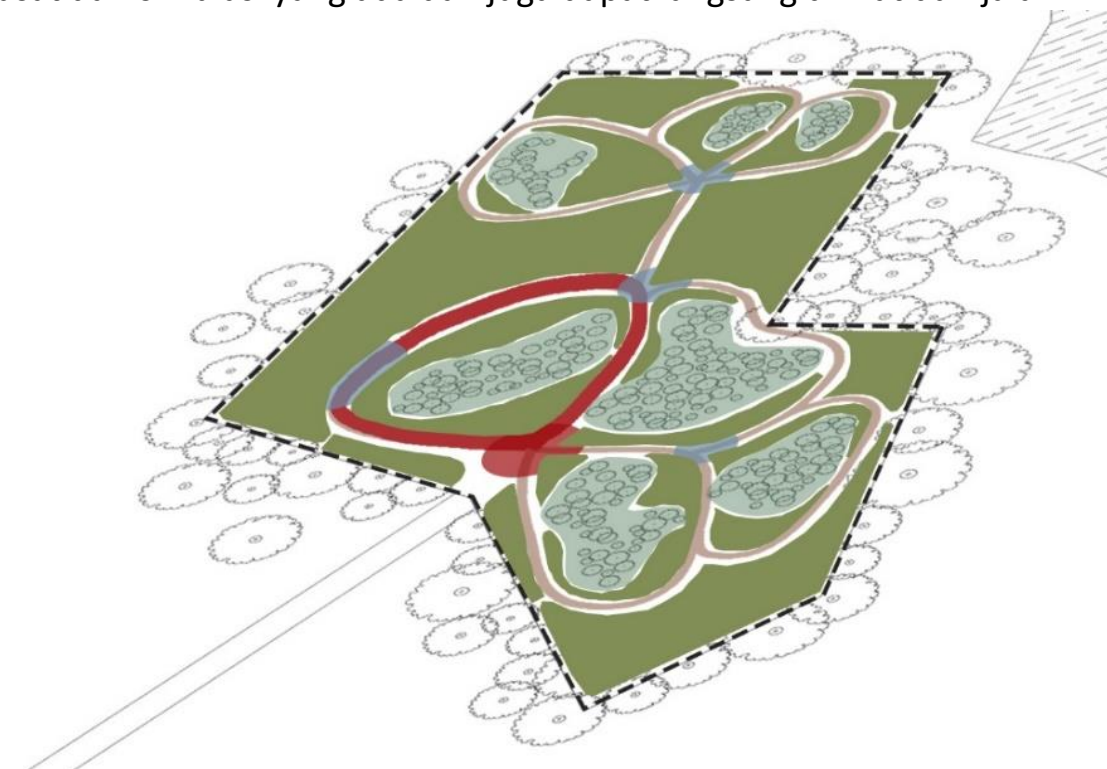

Gambar 9. Penentuan titik-titik peletakkan massa. Sumber: Penulis, 2021 
Setiap peletakkan massa mengikuti orientasi matahari guna untuk menangkap sinar matahari untuk keperluan energi listrik (lihat gambar 10). Selain itu adanya jalur setapak yang menjadi lorong angin untuk wind turbine. Peletakkan massa juga berdasarkan titik-titik nodes yang ada.

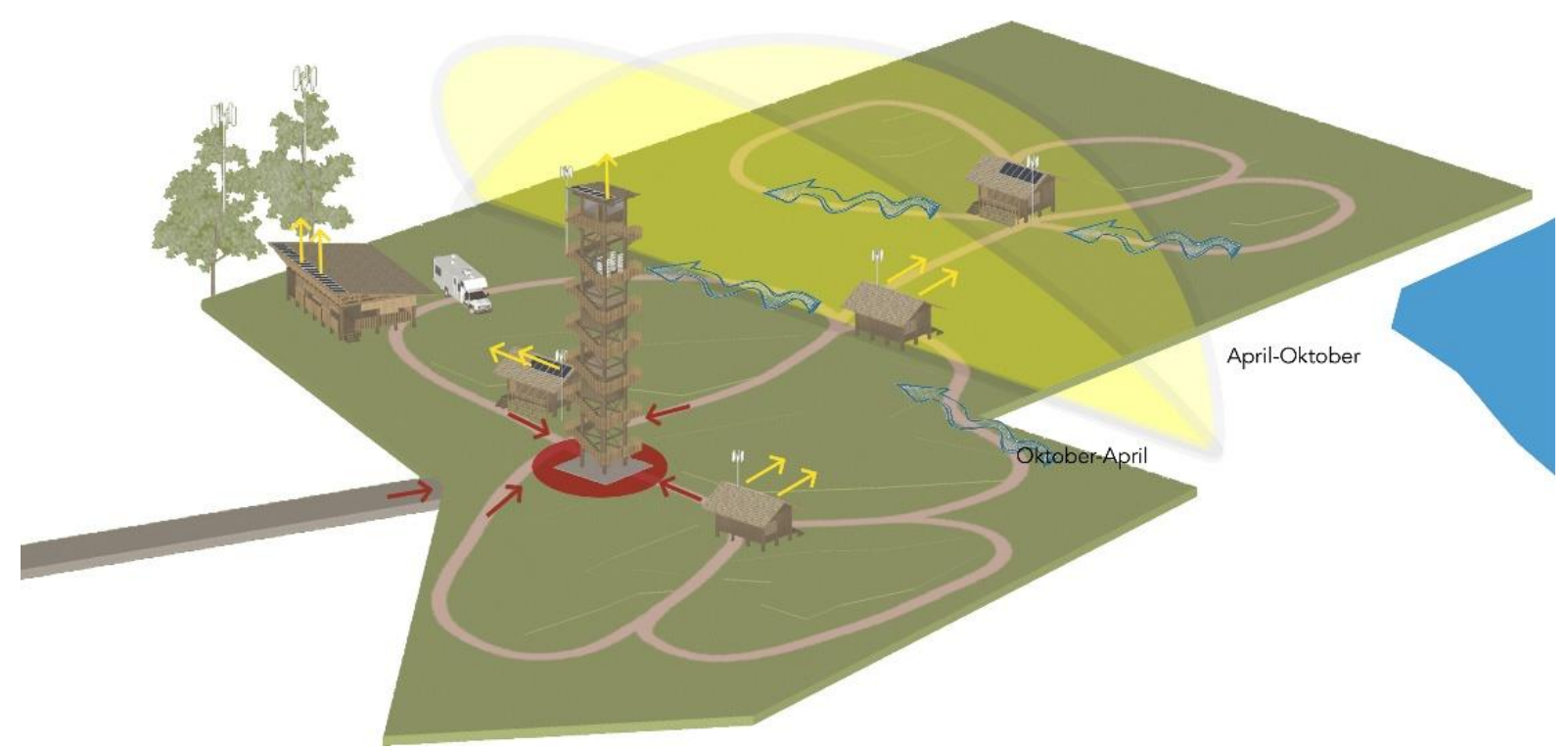

Gambar 10. Peletakkan final massa.

Sumber: Penulis, 2021

Menara observasi yang menjadi landmark dapat menjadi tempat untuk tinggal dan hidup dengan adanya hidroponik dan juga adanya tempat istirahat. Selain itu penggunaan wind turbine dan solar panel sebagai sumber energi listrik untuk kebutuhan pengawas yang berjaga. Atap memiliki kemiringan yang tidak terlalu curam agar penyerapan sinar matahari dapat lebih optimal (lihat gambar 11).

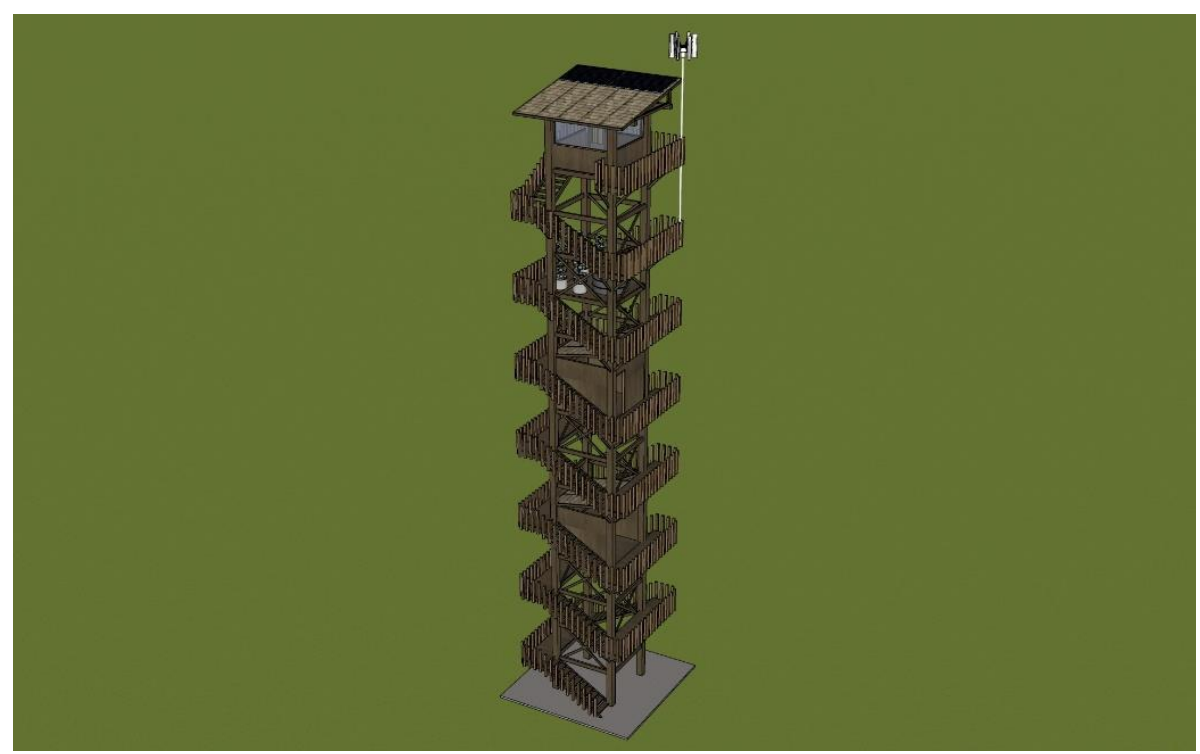

Gambar 11. Menara Observasi

Sumber: Penulis, 2021 
Area research bersifat terbuka dan minim akan sekat ruangan untuk mengantisipasi perubahan keguanaan. Sehingga area ini dapat bersifat feksibel sesuai dengan kebutuhan aktivitas yang sedang terjadi (lihat gambar 12).

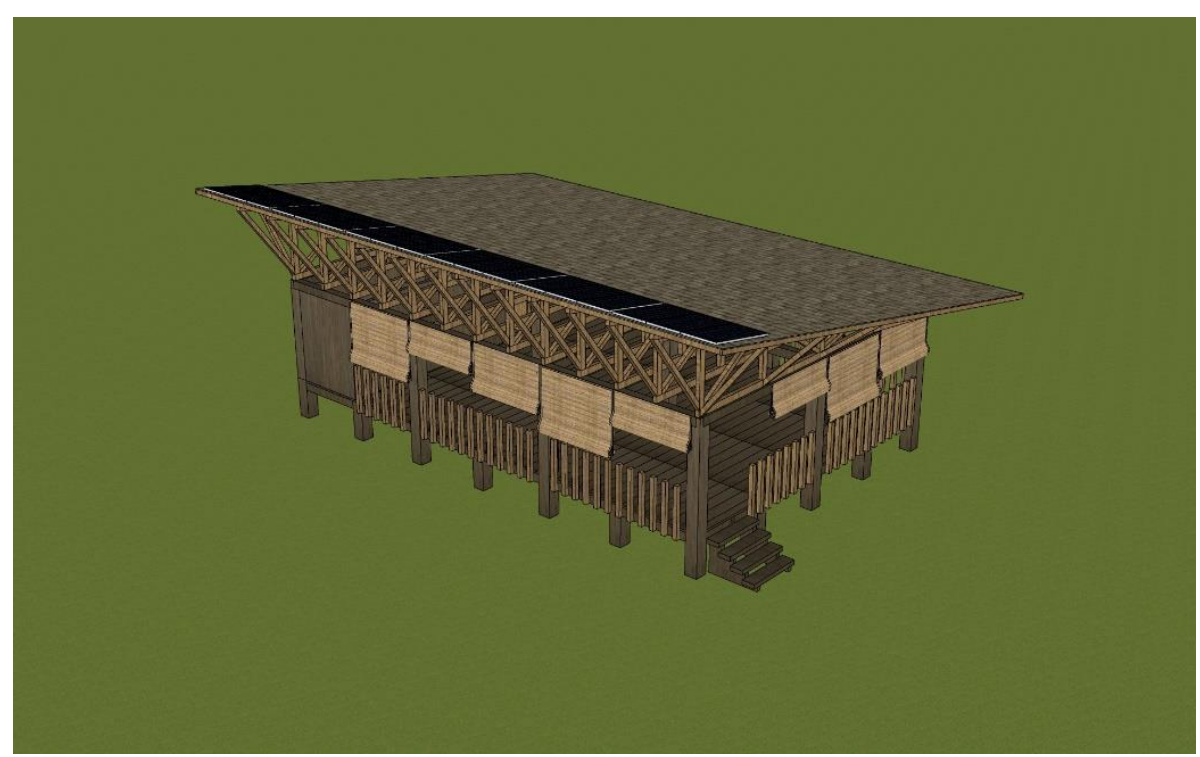

Gambar 12. Area Research

Sumber: Penulis, 2021

Tempat istirahat untuk para orang yang bertugas mereboisasi memiliki sumber listrik dan sumber air sendiri. Hal ini agar odul ini dapoat berdiri secara mandiri di tempat lain. Rumah ini juga memiliki rak pembibitan tanaman yang akan direboisasi

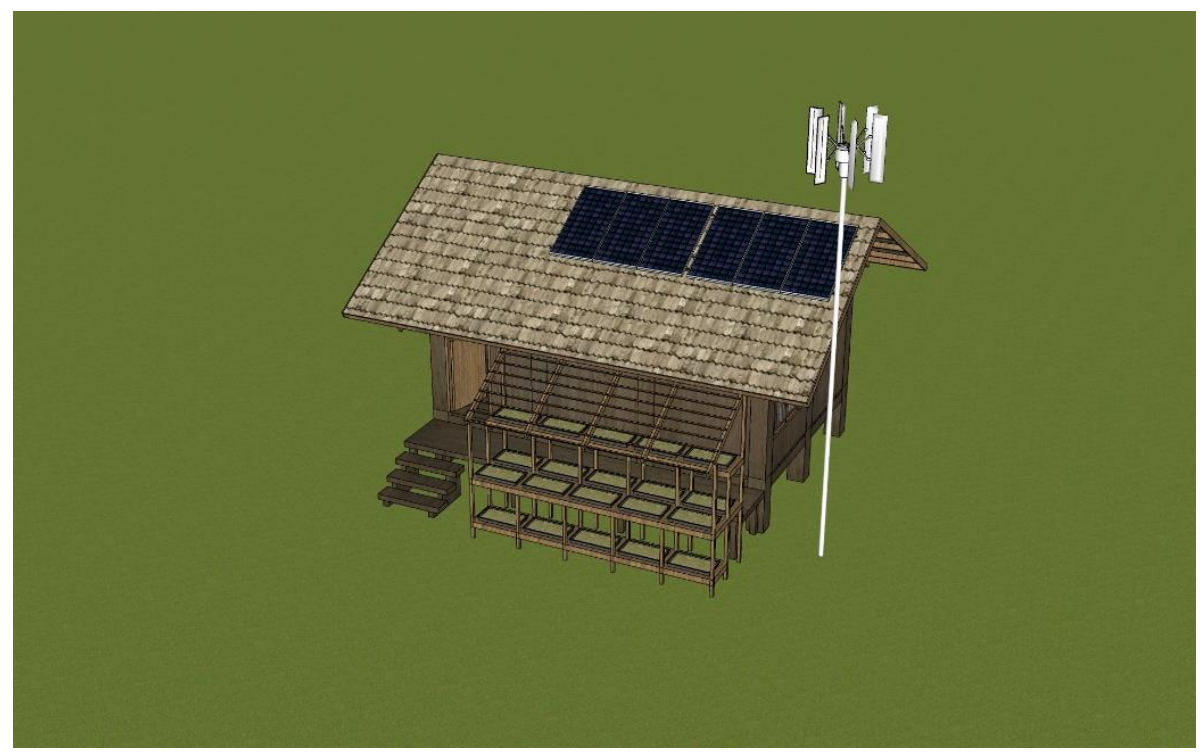

Gambar 13. Tempat Tinggal dan Rak Pembibitan

Sumber: Penulis, 2021 
Untuk mempermudah proses bongkar pasang ketika sebelum mereboisasi dan juga sesudah mereboisasi maka untuk setiap komponen bangunan dibuat sesuai dengan modul sambungan kayu yang ada (lihat gambar 14). Sistem sambungan yang digunakan lebih fokus ke sistem sambungan mur dan bout agar kayu tidak cepat rusak karena seringnya proses lepas pasang.

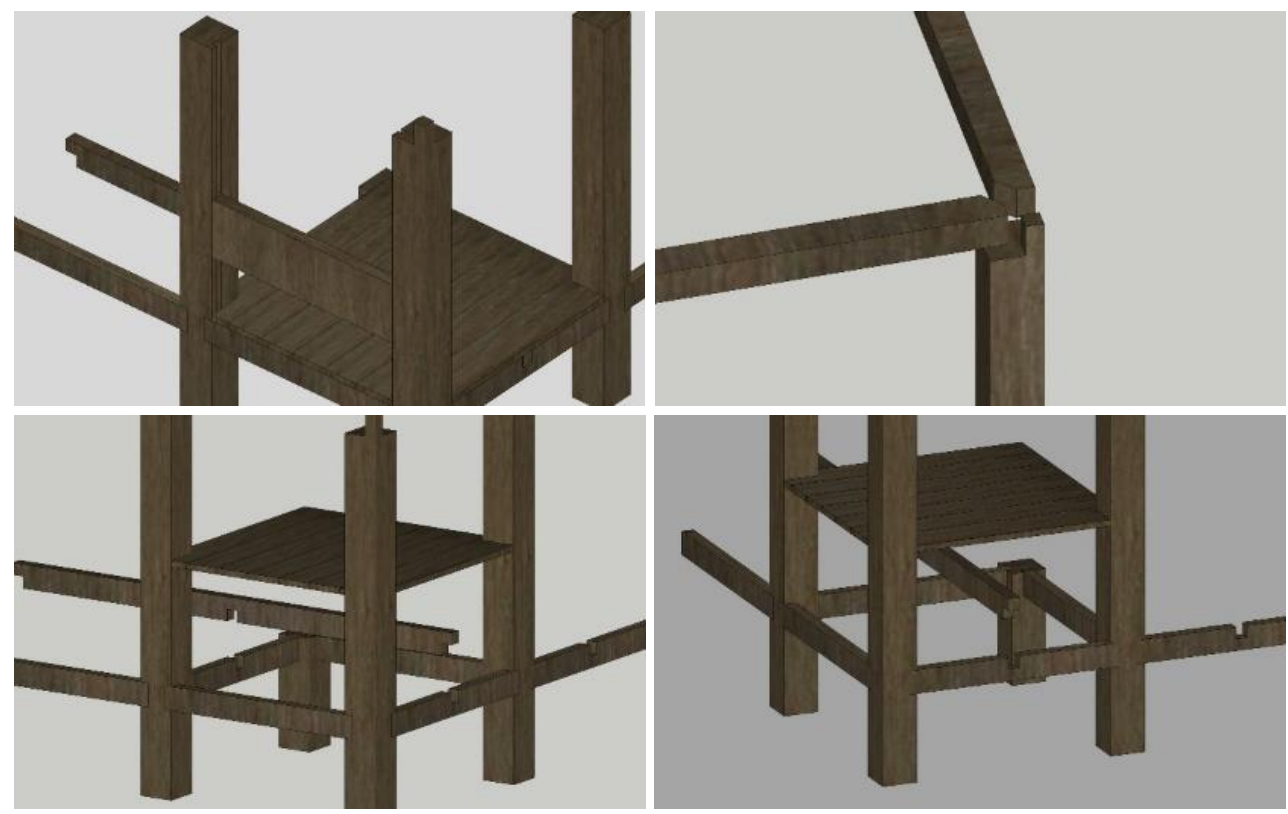

Gambar 14. Detail Sambungan

Sumber: Penulis, 2021

\section{KESIMPULAN}

Lahan hutan yang bekas terbakar menyebabkan hilangnya keanekaragaman hayati yang merupakan pondasi kehidupan bagi manusia. Permasalahan ini harus diatasi dengan mereboisasi hutan yang sebelumnya hilang. Dengan proyek ini menggunakan prinsip tektonik dan bongkar-pasang untuk memaksimalkan proses reboisasi, agar massa yang sudah tidak dipakai dapat dibongkar dan ditanami tumbuhan. Selain itu penempatan massa berdasarkan Kevin Lynch berdasarkan faktor-faktor kota yang ada dan diterapkan dalam hutan. Dan setelah terselesaikannya reboisasi ini massa-massa yang digunakan untuk reboisasi dan telah tidak digunakan akan dibongkar dan dipindahkan ke kawasan lainnya yang membutuhkan untuk reboisasi. Khusus untuk menara observasi ini akan tetap dan tidak akan dibongkar karena menjadi massa untuk mengawasi hutan di sekelilingnya. Untuk mendukung proses pengawasan yang ada, maka adanya fasilitas pendukung bagi para individu yang akan mengawasi, seperti tempat tinggal, toilet, dapur, dan hidroponik sebagai sumber makanan.

\section{REFERENSI}

Arief W., N. S. (2019, Juli 21). Indonesia Telah Mengurangi Penggundulan Hutan, tetapi Masalah Masih Ada. Dipetik Maret 21, 2021, dari WRI Indonesia: https://wriindonesia.org/id/blog/indonesia-telah-mengurangi-penggundulan-hutan-tetapi-masalahmasih-ada

Baskoro, B. (2019, Agustus 22). Kebakaran Hutan dan Lahan Kalteng, Palangkaraya dan Pulang Pisau Paling Rawan. Dipetik Maret 21, 2021, dari Mongabay: https://www.mongabay.co.id/2019/08/21/kebakaran-hutan-dan-lahan-kaltengpalangkaraya-dan-pulang-pisau-paling-rawan/

Capra, F. (1997). The Web of Life: A New Scientific Understanding of Living Systems. New York: Doubleday. 
Capra, F. (2013). Deep Ecology: Educational Possibilities for Twenty-First Century. The North American Montessori Teachers' Association (NAMTA) Journal, 38(1), 201-2016. Diambil kembali dari https://files.eric.ed.gov/fulltext/EJ1078054.pdf

Carter, N. H., Shrestha, B. K., Karki, J. B., Pradhan, N. M., \& Liu, J. (2012). Coexistence between Wildlife and Humans at Fine Spatial Scales. Proceedings of the National Academy of Sciences of the United States of America (hal. 15360-15365). California: National Academy of Sciences. doi:https://doi.org/10.1073/pnas.1210490109

Frampton, K. (2004). Labour, Work and Architecture. London: Phaidon.

Hardjasoemantri, K. (2006). Hukum Tata Lingkungan, Edisi VIII, Cetakan Kesembilan Belas. Yogyakarta: 2006.

Jonathan H., A. F. (Sutradara). (2020). A Life on Our Planet [Gambar Hidup]. Dipetik Februari 1, 2021, dari https://www.netflix.com/id-en/title/80216393

Jørgensen, S. E. (2009). Ecosystem Ecology. Cambridge: Academic Press.

Kemendikbud. (2021, Februari 16). Kamus Besar Bahasa Indonesia (KBBI). Dipetik Februari 16, 2021, dari KBBI: https://kbbi.web.id/ekologi

Keraf, A. S. (2006). Etika Lingkungan. Jakarta: PT. Kompas Media Nusantara.

Lynch, K. (1960). The Image of the City. Cambridge: The M.I.T. Press.

Pianka, E. R. (1988). Evolutionary Ecology. Fourth Edition. New York: Harper and Row.

Sutanto, A. (2020). Peta Metode Desain. 